\title{
Age-related qualitative shift in emotional behaviour: Paradoxical findings after re-exposure of rats in the elevated-plus maze
}

\author{
J.M. Bessa ${ }^{\text {a }}$, M. Oliveira ${ }^{\text {a }}$, J.J. Cerqueira ${ }^{\text {a }}$, O.F.X. Almeida ${ }^{b}$, N. Sousa ${ }^{a}, *$ \\ ${ }^{a}$ Neuroscience Group, Life and Health Science Research Institute (ICVS), University of Minho, Campus de Gualtar, 4710-057 Braga, Portugal \\ ${ }^{\mathrm{b}}$ Neuroadaptations Group, Max-Planck Institute for Psychiatry, Munich, Germany
}

Received 23 December 2004; received in revised form 10 March 2005; accepted 13 March 2005

Available online 12 April 2005

\begin{abstract}
Several variables, including age, are known to influence anxiety. Previous exposure to the elevated-plus maze (EPM) is known to modify emotional behaviour as retesting in the EPM at a standard age of 3 months increases open-arm avoidance and attenuates the effects of anxiolytic drugs. This study analysed whether similar results are obtained when older animals are subjected to these experimental paradigms. Overall, increasing age was associated with more signs of anxiety. Additionally, we observed a paradoxical behaviour pattern in aged-subjects that were re-exposed to the EPM, with mid-aged and old rats failing to display open arm avoidance (OAA) in the second trial; this qualitative shift in emotional behaviour was not associated with decreased locomotion. An examination of how age influences responsiveness to anxiolytic drugs, with or without previous maze experience, was also conducted. Midazolam $(0.5 \mathrm{and} 1 \mathrm{mg} / \mathrm{kg})$ proved anxiolytic in maize-naive young animals; in marked contrast, in older animals midazolam at $1 \mathrm{mg} / \mathrm{kg}$ resulted in sedation but not anxiolyis. One trial tolerance to midazolam was evident in animals of both ages that were subjected to a second EPM trial; the latter phenomenon was apparently accentuated in older animals as they do not show open arm avoidance upon re-exposure to the EPM. These data suggest that the age-associated 'resistance' to anxiolytic drugs might be related to a qualitative shift in emotional behaviour.
\end{abstract}

(C) 2005 Elsevier B.V. All rights reserved.

Keywords: Aging; Anxiety; Open arm avoidance; One trial tolerance; Risk assessment; Elevated-plus maze; Rat

\section{Introduction}

The elevated-plus maze (EPM) is currently the most popular and reliable animal test to evaluate anxiety behaviour in rodents [21,33]. It relies on the conflict of the natural aversion of rodents to open spaces with the drive to explore a new environment [42] and has been extensively validated [27,32]; in accordance, it has proven to be essential in the screening of new anxiolytic drugs [11]. There are several variables known to influence behaviour in EPM [33]; briefly, they can be divided in those depending on the subject (e.g. specie, strain, gender and age) and those depending on environment (e.g. housing, prior handling or stress, lighting levels). Previous exposure to the maze is recognized as an important modi-

\footnotetext{
* Corresponding author. Tel.: +351253 604806; fax: +351253604809.

E-mail address: njcsousa@ecsaude.uminho.pt (N. Sousa).
}

fier of performance; indeed, retest of rodents in the EPM increases open arm avoidance (OAA) [2,12,16,19,23,34-36]. This OAA effect seems to be progressive, starting around the second minute of trial 1 and may even increase with further retesting $[22,35]$.

Prior maze experience is also known to reduce or even abolish the anxiolytic effects of drugs that bind to the GABA-A receptor complex such as benzodiazepines, ethanol or phenobarbital $[3,15,17,34]$, as well as drugs that block NMDA/glycine-B receptor activity such as memantine [4]. This loss of anxiolytic effect of drugs in the trial 2 of the EPM, designated as "one trial tolerance" (OTT) [14], has also been observed in other animal models of anxiety [20,24,30]. The phenomenon of OTT, which seems to be independent of the drug treatment on trial 1 or the material of the maze [14], occurs with inter-test intervals ranging from $24 \mathrm{~h}$ to 2 weeks $[14,34]$. 
Different hypotheses have been advanced to explain the effect of prior maze experience in the increase of OAA and the phenomenon of OTT such as locomotor habituation [12], acquisition of a phobic avoidance of open arms [15,34] or a qualitative shift in the emotional state during trial 2 [22]. Yet, the ethologic and biologic significance of the behavioural changes elicited by prior maze experience still remain unclear.

Changes in emotional behaviour represent one of the most important aspects of aging in both humans and rodents. Taking into account the altering behaviour patterns of rats with different ages in the EPM [6,25] and the relevance of prior experiences in the process of avoidance learning we designed the present study to further characterise the effect of prior maze exposure on the increase of OAA and the OTT phenomenon in different stages of the rat adult lifetime.

\section{Materials and methods}

\subsection{Animals}

Male Wistar rats (Charles Rivers Laboratories, Barcelona, Spain), aged 2, 3, 12 and 18 months were used; the weights of animals aged between 2 and 3 months ranged between 200 and $350 \mathrm{~g}$ while the older animals weighed 500 and $750 \mathrm{~g}$. Animals were housed in a room adjacent to the laboratory, in groups of four (cage size $60 \mathrm{~cm} \times 40 \mathrm{~cm} \times 20 \mathrm{~cm}$ ), under standard laboratory conditions with an artificial light/dark cycle of $12 / 12 \mathrm{~h}$ (lights on at 8 a.m.), temperature of $22{ }^{\circ} \mathrm{C}$ and free access to food and water. Animals were taken to the test laboratory at least $1 \mathrm{~h}$ prior to testing and all experimental sessions were conducted during the diurnal phase, between 12:00 and 18:00 h. All procedures were carried out in accordance with European Union Directive 86/609/EEC and NIH guidelines on animal care and experimentation.

\subsection{Apparatus}

The EPM was made of black polypropylene (ENV560; MedAssociates, VT, USA), consisted of two opposite open arms $(50.8 \mathrm{~cm} \times 10.2 \mathrm{~cm})$ and two enclosed arms $(50.8 \mathrm{~cm} \times 10.2 \mathrm{~cm} \times 40.6 \mathrm{~cm})$ elevated $72.4 \mathrm{~cm}$ above the floor. The junction area between the four arms measured $10 \mathrm{~cm} \times 10 \mathrm{~cm}$. A raised edge $(0.5 \mathrm{~cm})$ on the open arms provided additional grip for the rats.

\subsection{Procedures}

The experimental room was lit by $40 \mathrm{~W}$ fluorescent lamps mounted above the maze so that all arms were equally illuminated ( $3001 \mathrm{x}$ at the maze floor level). Rats were placed individually in the centre of the maze facing a closed arm and were allowed 5 min of free exploration. Behavioural parameters were recorded with the use of an infra-red photobeam system connected to a computer with specific software (MedPCIV, MedAssociates, VT, USA). After each trial, the maze was cleaned with a $10 \%$ ethanol solution.

\subsection{Evaluation of the open arm avoidance effect}

To evaluate the OAA effect, the 48 rats used were divided into four different age groups $(n=12)$ of 2, 3, 12 and 18 months respectively. The animals were submitted to two trials in the EPM, with an intertrial interval of $24 \mathrm{~h}$.

\subsection{One trial tolerance to midazolam}

Among the 90 rats used to assess the OTT phenomenon to midazolam, 47 were maze-naive while 43 were pre-exposed to the EPM with an intertrial interval of $24 \mathrm{~h}$ without drug treatment (mazeexperienced). Both groups were subdivided in two different age groups (3 and 12 months). Within each group, animals were randomly allocated to different treatment conditions ((saline, $n=8 ; 0.5$, $n=7$ or $1, n=7) \mathrm{mg} / \mathrm{kg}$ midazolam). The injection-test interval employed was $15 \mathrm{~min}$. Midazolam (Roche, Switzerland) was dissolved shortly before use in a $0.9 \%$ saline solution (which, alone, served as a vehicle control). The solutions were administered intraperitoneally in a volume of $0.15 \mathrm{ml} / 100 \mathrm{~g}$.

\subsection{Behavioural analysis}

The standard behavioural parameters analysed for each animal in the EPM were the amount of time spent in the central area, open and closed arms, the number of entries in the open and closed arms and the number of explorations of the open arms. In addition, these data were used to calculate the number of entries in the closed arms as a general locomotion activity measure, the percentage of time spent in open arms (\%OT: open arm time $/ 300 \times 100)$, the percentage of open arm entries [\%OE: open entries/(open + closed entries) $\times 100$ ] and the risk assessment (RA) behaviour defined as follows: $\mathrm{RA}=$ [number of explorations/ $(300-$ open arm time $)] \times 60$. The RA measure allows estimating the frequency of explorations from protected areas of the maze per minute and has proven to be very sensitive to changes in anxiety behaviour $[10,18]$. Measures of variation between trial 1 and 2 were calculated for the percentages of open arm time and open arm entries.

\subsection{Statistics}

In the evaluation of the open arm avoidance effect, data from both trials was analysed by two-factor (age group $\times$ trial) repeated measures analysis of variance (ANOVA). The one trial tolerance to midazolam was analysed by three-factor (age group $\times$ maze experience $\times$ drug) analysis of variance (ANOVA). Between-subjects effects were assessed by one-way analysis of variance (ANOVA). Differences between groups were then determined by a Tukey's honestly significant difference test (Tukey HSD) post hoc analysis. The results are expressed as group means \pm standard error. Statistical significance was accepted for a probability level below 0.05 .

\section{Results}

\subsection{Evaluation of the open arm avoidance effect}

As illustrated in Table 1, the repeated measures analysis of variance (ANOVA) performed revealed significant effect 
Table 1

Two-factor (age group $\times$ trial) repeated measures ANOVA

\begin{tabular}{lll}
\hline Parameter & Age group $($ d.f. $=3.90)$ & Trial $($ d.f. $=1.90)$ \\
\hline$\%$ Open arm time & $F=6.684 ; p<0.001$ & $F=77.794 ; p<0.001$ \\
$\%$ Open arm entries & NS & $F=212.795 ; p<0.001$ \\
Closed arm entries & $F=14.383 ; p<0.001 \quad$ NS \\
Risk assessment & $F=28.095 ; p<0.001 \quad F=6.465 ; p=0.001 \quad$ NS \\
\hline
\end{tabular}

d.f., degrees of freedom; NS, non-significant.

of age for all the parameters evaluated, except for the $\%$ of open arm entries. A significant effect of trial was found in all the parameters evaluated in the EPM except in the closed arm entries. Furthermore, this analysis revealed interactions between age and trial in the $\%$ of open arm time and risk assessment behaviour.

In trial 1 , a progressive reduction of the $\%$ of time spent in the open arms of the EPM was observed with increasing age of maze naive rats. In trial 2, maze-experienced rats revealed a progressive increase in this parameter with increasing age, except for the rats of 18 months (Fig. 1).

The intertrial differences analysis, revealed a significant reduction in the $\%$ of time spent in the open arms in trial 2 in rats of 2 months $\left(F_{(1,23)}=12.645, p=0.001\right)$ and 3 months $\left(F_{(1,23)}=4.397, p=0.047\right)$, confirming the OAA effect previously described. Surprisingly, in older rats [12 months $\left(F_{(1,23)}=6.119, p=0.003\right)$ and 18 months $\left(F_{(1,23)}=5.513\right.$, $p=0.027)]$, there was an opposite effect, with a significant increase in the $\%$ of time spent in open arms in trial 2.
For the $\%$ of open arm entries, the same behavioural pattern was observed, with a significant decrease in trial 2 in rats of 2 months $\left(F_{(1,23)}=5.539, p=0.026\right)$ and 3 months $\left(F_{(1,23)}=8.777, p=0.007\right)$ but an increase, although not statistically significant in rats of 12 and 18 months of age (Fig. 1).

The one-way ANOVA performed revealed significant differences in the variation in $\%$ of time spent in open arms (T2-T1), between younger rats of 2 months and older rats of 12 months $(p<0.001)$ and 18 months $(p=0.001)$ and between rats of 3 and 12 months $(p=0.005)$. The variation in the $\%$ of open arm entries (T2-T1) was significantly different between younger rats of 2 months and $12(p=0.012)$ and 18 months $(p=0.043)$ old rats, as well as between rats of 3 and 12 months $(p=0.02)$.

In the risk assessment behaviour parameter, significant intertrial differences were found in animals aged 2 months $(p<0.001)$ and 18 months $(p<0.001)$; in both cases, there was an increase in risk assessment behaviour in the second trial. No significant intertrial differences were observed in
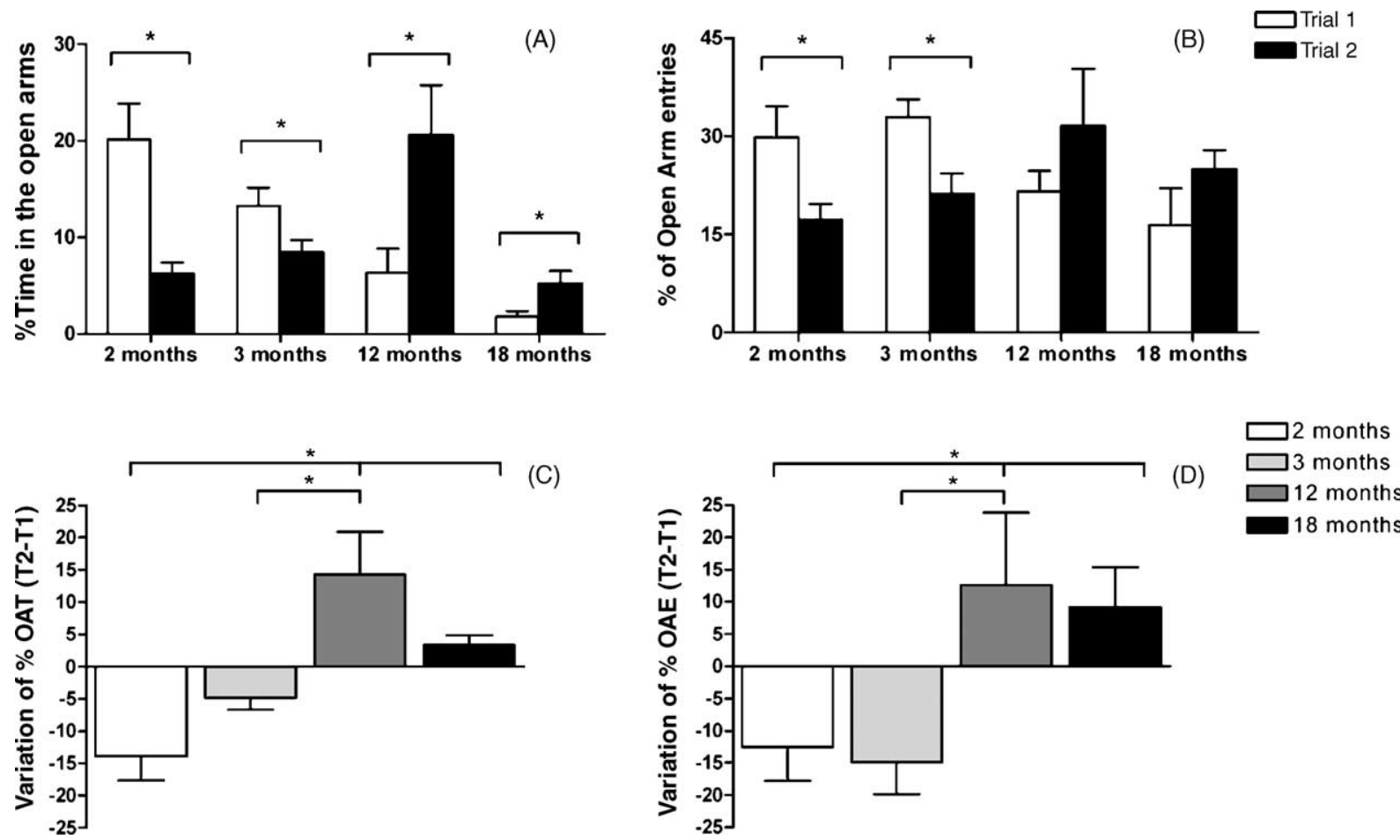

Fig. 1. Changes in the percentage of time spent in the open arms (A) and percentage of open arm entries (B) in the first and second trial. Variation of the percentage of time spent in open arms (C) and percentage of open arm entries (D) between trials (T2-T1). ${ }^{*} p<0.05$. Data are presented as mean \pm S.E.M. OAT, open arm time; OAE, open arm entries. 

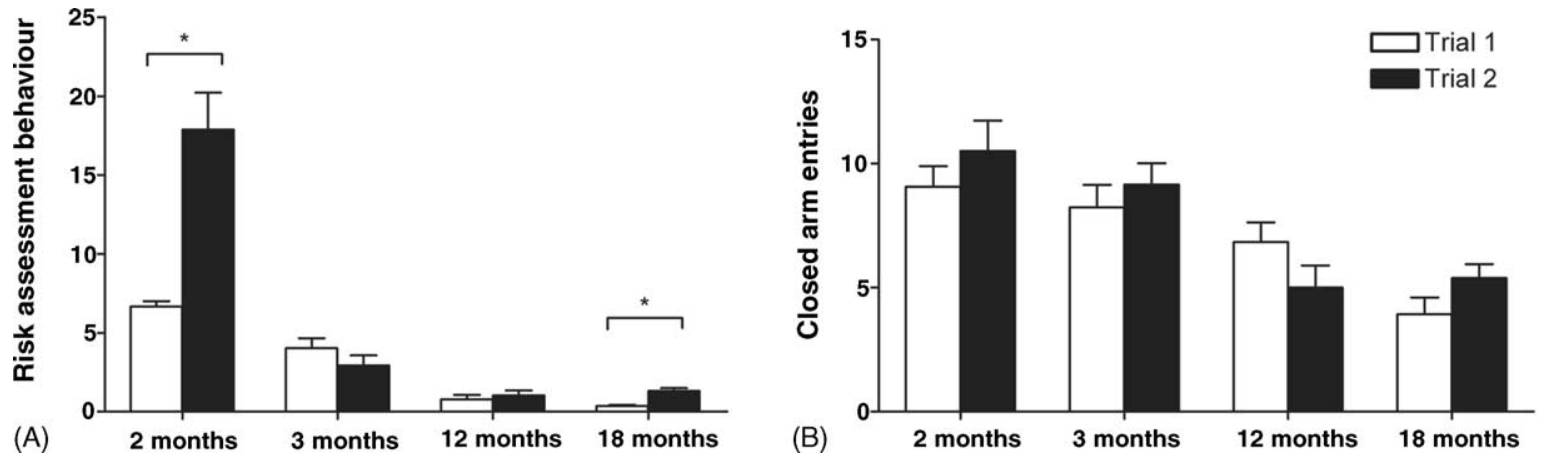

Fig. 2. Intertrial differences in risk assessment behaviour (A) and total number of closed arm entries (B) in different age groups. ${ }^{*} p<0.05$. Data are presented as mean \pm S.E.M.

the 3- and 12-month groups. Interestingly, there was a progressive decline with increasing age in this parameter in trial 1 (Fig. 2).

As a measure of general locomotor activity, the number of entries in the closed arms failed to reveal any significant intertrial differences between age groups. However, a progressive decrease in this parameter was observed with increasing age, except for the second trial in the rats of 18 months (Fig. 2).

\subsection{One trial tolerance to midazolam}

Table 2 illustrates the three-factor $($ age $\times$ drug $\times$ maze experience) analysis of variance (ANOVA) performed to assess the one trial tolerance to midazolam that revealed a significant main effect of age for all the parameters evaluated. A significant effect of maze experience was found for all the parameters evaluated except for the number of closed arm entries. The effect of drug was only significant for the number of closed arm entries and risk assessment behaviour. Furthermore, this analysis revealed significant interactions between age and drug for the $\%$ of open arm time, age and maze experience for all the parameters evaluated, drug and maze experience for all the parameters except risk assessment behaviour and between the three factors for the number of closed arm entries.

In accordance with the results of the OAA evaluation, significant differences between maze naive and mazeexperienced rats were found within the saline treated groups of different age. Maze-experienced rats at 3 months of age revealed lower $\%$ of open arm time $\left(F_{(1,25)}=4.397, p=0.047\right)$ and lower $\%$ of open arm entries $\left(F_{(1,25)}=98.321, p=0.04\right)$ whilst maze-experienced rats of 12 months revealed a higher $\%$ of open arm time $\left(F_{(1,11)}=6.119, p=0.033\right)$.

As illustrated in Fig. 3, in maze naive rats of 3 months, significant differences were found between the saline treated group and the midazolam $(1 \mathrm{mg} / \mathrm{kg})$ treated group that revealed a higher $\%$ of time in the open arms $\left(F_{(2,26)}=3.952\right.$, $p=0.04)$ and higher $\%$ of open arm entries $\left(F_{(2,26)}=3.483\right.$, $p=0.044)$. Maze-experienced rats of 3 months treated with midazolam $(1 \mathrm{mg} / \mathrm{kg})$ revealed a significant lower $\%$ of open arm time $\left(F_{(2,22)}=3.667, p=0.035\right)$ compared to the saline treated group and failed to reveal significant differences in the $\%$ of open arm entries, thereby confirming the one trial tolerance to midazolam previously described.

In maze naive rats of 12 months no significant differences were found between treatment groups regarding the \% of time spent in the open arms and the \% of open arm entries. Maze-experienced rats of 12 months treated with midazolam $(1 \mathrm{mg} / \mathrm{kg})$ revealed a significantly lower \% of open arm time $\left(F_{(2,19)}=8.252, p=0.002\right)$ compared with the saline treated group and a lower, although not significant, \% of open arm entries.

Concerning the number of closed arm entries (Fig. 3), maze naive rats of 12 months treated with midazolam $(1 \mathrm{mg} / \mathrm{kg})$ revealed a significant lower locomotor activity compared with the saline $\left(F_{(2,19)}=9.361, p=0.002\right)$ and midazolam $(0.5 \mathrm{mg} / \mathrm{kg})$ treated group $\left(F_{(2,19)}=9.361\right.$, $p=0.01)$. Maze-experienced rats of 12 months treated with midazolam $(1 \mathrm{mg} / \mathrm{kg})$ showed a lower locomotor activity compared with midazolam $(0.5 \mathrm{mg} / \mathrm{kg})$ treated group

Table 2

Three-factor (age $\times$ drug $\times$ maze experience) ANOVA

\begin{tabular}{|c|c|c|c|c|}
\hline Parameter & $\%$ Open arm time & $\%$ Open arm entries & Closed arm entries & Risk assessment \\
\hline Age $($ d.f. $=1.90)$ & $F=6.799 ; p=0.011$ & $F=7.006 ; p=0.01$ & $F=41.622 ; p<0.001$ & $F=41.285 ; p<0.001$ \\
\hline Drug (d.f. = 1.90) & NS & NS & $F=9.890 ; p<0.001$ & $F=3.325 ; p=0.041$ \\
\hline Maze experience $($ d.f. $=1.90)$ & $F=8.178 ; p=0.005$ & $F=18.625 ; p<0.001$ & NS & $F=6.971 ; p=0.01$ \\
\hline Age $\times$ drug & $F=6.197 ; p=0.003$ & NS & NS & NS \\
\hline Age $\times$ maze experience & $F=39.502 ; p<0.001$ & $F=15.714 ; p<0.001$ & $F=7.083 ; p=0.006$ & $F=6.854 ; p=0.011$ \\
\hline Drug $\times$ maze experience & $F=10.064 ; p<0.001$ & $F=5.023 ; p=0.009$ & $F=5.255 ; p=0.007$ & NS \\
\hline Age $\times$ drug $\times$ maze experience & NS & NS & $F=4.225 ; p=0.018$ & NS \\
\hline
\end{tabular}

d.f., degrees of freedom; NS, non-significant. 


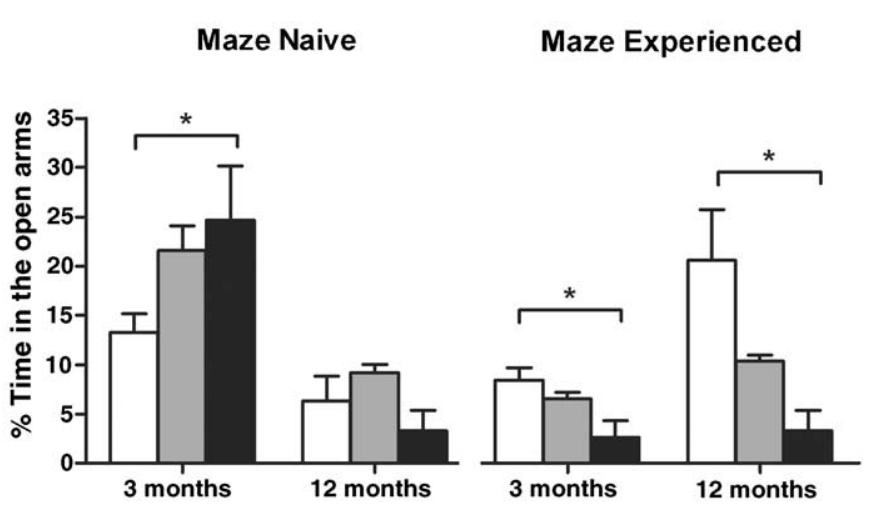

(A)
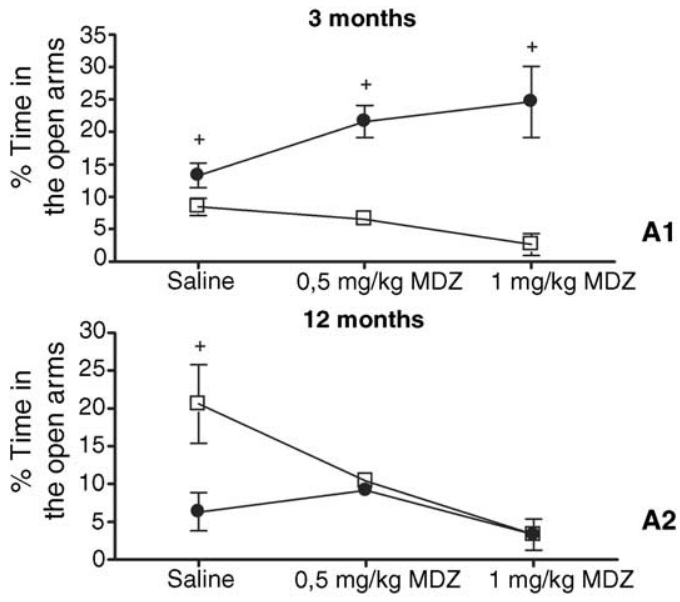

Maze naive $\square$ Maze experienced

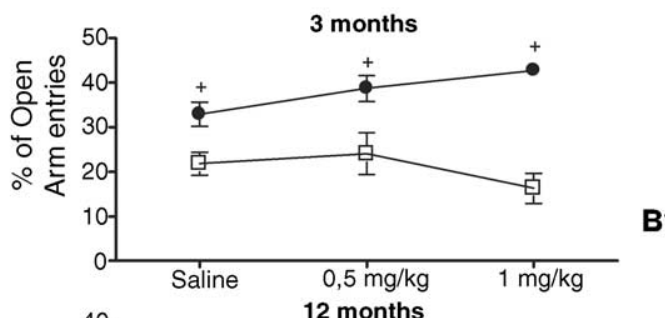

B1

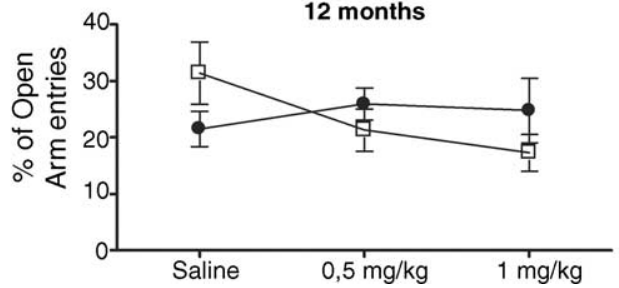

Fig. 3. (A) Effects of midazolam on the $\%$ of time spent in the open arms. The insets compare $\%$ of open arm time in maze-naive and maze-experienced rats given different doses of midazolam at 3 (A1) and 12 (A2) months of age. (B) Effects of midazolam on the \% of entries in the open arms. Insets show the effects of different doses of midazolam on the \% of open arm entries in maze-naive and maze-experienced rats at 3 (B1) and 12 (B2) months of age. (*) Statistical differences between treatment groups + statistical differences between maze-naive and maze-experienced groups. Data are presented as mean \pm S.E.M.

$\left(F_{(2,19)}=7.085, p=0.0014\right)$ which revealed a higher locomotor activity compared with the saline treated group $\left(F_{(2,19)}=7.085, p=0.0013\right)$. In the age group of 3 months, significant differences in this parameter were exclusively found in maze-experienced rats in which the midazolam $(0.5 \mathrm{mg} / \mathrm{kg})$ treated group revealed higher scores compared to saline $\left(F_{(2,22)}=7.167, p=0.021\right)$ and midazolam $(1 \mathrm{mg} / \mathrm{kg})$ $\left(F_{(2,22)}=7.167, p=0.004\right)$ treated rats.

In the risk assessment behaviour parameter, significant differences were confined to the maze-experienced rats of 3 months, in which the midazolam $(0.5 \mathrm{mg} / \mathrm{kg})$ treated group revealed a higher score compared with the saline $\left(F_{(2,22)}=8.834, p=0.01\right)$ and midazolam $(1 \mathrm{mg} / \mathrm{kg})$ $\left(F_{(2,22)}=8.834, p=0.028\right)$ treated rats (Fig. 4$)$.

\section{Discussion}

Aging is a multifactorial process that leads to neurobehavioral declines, although at different rates. Changes in emo- tional behaviour, including increased anxiety behaviour, represent one of the most important aspects of aging. This is perfectly illustrated by the analysis of medical prescription in aged persons, which is characterised by a significant increase in the use of anxiolytic drugs [9]. In accordance with other studies in rodents $[6,25]$, we observed in the first trial of the EPM a progressive decrease in the \% of time spent in the open arms and locomotor activity with increasing age. Interestingly, the $\%$ of time spent in the open arm declined consistently from the younger (2-month-old) to the older (18month-old) groups of animals tested; age-associated declines in open arm entries, another marker of anxiety, were less obvious.

Also in agreement with literature $[2,12,16,19,23,34]$ our results confirm that retesting young adults (2- and 3-monthold animals) in the EPM increases open arm avoidance, as shown by the significant decrease of the $\%$ of time and open arm entries in the second trial. Rather surprisingly, an opposite effect was observed in mid-age rats (12 months) and old 

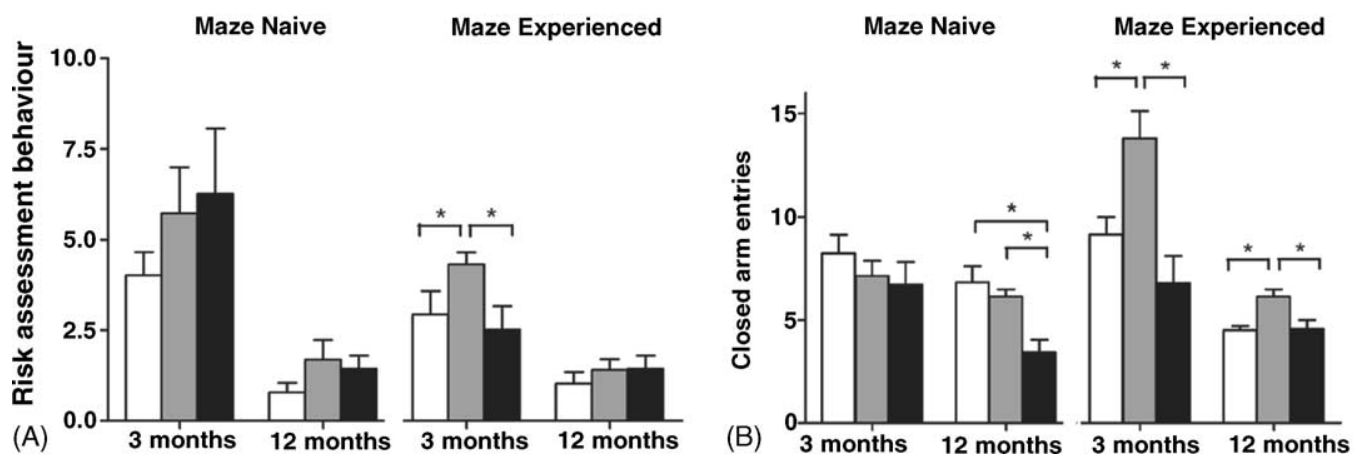

Fig. 4. Midazolam (0.5-1 mg/kg) effects on risk assessment behaviour (A) and total number of closed arm entries (B), in both maze-naive and maze-experienced (drug-naive) rats submitted to the EPM. $\left({ }^{*}\right)$ Statistical differences between treatment groups. Data are presented as mean \pm S.E.M.

rats (18 months), in which retesting produced a significant increase in the \% of time spent in the open arms of the EPM in trial 2.

The mechanisms underlying both OAA and OTT are far from completely understood. It has been hypothesized that fear cues, known to be rapidly acquired during trial 1, might trigger endocannabinoid activation on plus-maze trial 2 [37]. Of direct relevance to this line of argument is a recent report that re-exposure to learned fear cues selectively increases endocannabinoid levels in the basolateral amygdala [28], an area of brain crucial for emotional behaviour. Endocannabinoid increases become further relevant, when considering that activation of presynaptic cannabinoid receptors inhibits neurotransmitter release in several areas of the brain [13,39] reducing particularly the GABAergic neurotransmission in limbic regions $[1,7,31,38,40,43]$ a fact that might lead to increase basal anxiety relative to trial 1 .

Because endocannabinoids are involved in learning and memory processes [8], their implication in OAA becomes further supported by observations showing that drugs (e.g. scopolamine) interfering with learning acquisition can blunt the OTT phenomenon [5]. Given that age is characteristically associated with impairments in learning processes, including fear conditioning [26], one might speculate that age-induced deficits in fear acquisition might be essential to the absence of avoidance to the open arm in re-exposures to the EPM. Furthermore, it has been recently shown that CB1 endocannabinoid receptor expression and activity is decreased with age in humans [29].

Irrespective of the mechanisms underlying the open arm avoidance phenomenon and the age-associated differences herein described, analysis of data allows us to rule out locomotor habituation [12] as a key factor in its genesis. In fact, although aging was associated with decreased activity, comparison of closed-arm entries between trials did not reveal significant variation in general locomotion activity in any of the age groups studied.

Repeated measures analysis of variance confirmed a significant effect of age in risk assessment behaviour, with a progressive decrease of risk assessment behaviour with aging, in both trials. However, significant intertrial variations in this parameter were confined to the youngest (2-monthold) or oldest (18-month-old) groups, in which there was an increased risk assessment in re-exposure to the EPM. This observation demonstrates that both developing (immature) and senescent rats display a different exploratory strategy when re-exposed to an anxiety model, suggesting a curious age-associated quantitative shift in anxious behaviour in age extremes.

Administration of midazolam to young maze-naive rats produced an anxiolytic effect; as expected, the anxiolytic effects of midazolam were compromised in young mazeexperienced rats. Curiously, the age of the subject affected the response to these drugs, as in older animals similar doses of midazolam failed to produce significant anxiolytic effects, suggesting an increased "resistance" and/or reduced density of GABA-A receptors in aged-subjects. Furthermore, $1 \mathrm{mg} / \mathrm{kg}$ of midazolam produced sedation in older animals, a finding that is in agreement with previous observations that the behavioural effect of benzodiazepines in aged rats favours a sedative profile in detriment of their anxiolytic actions [43].

Despite significant interactions between age, drug and maze experience, these factors influenced behaviour differently: while, age was the major determinant of the locomotion (closed arm entries) and risk assessment behaviour, previous maze experience had the greatest influence on anxiety behaviour (\% of time in open arms and \% of open arm entries). Interestingly the latter factor per se failed to influence the number of closed arm entries (locomotion). Importantly, when assessing the one trial tolerance phenomenon to midazolam in different ages it becomes clear that the latter is preserved independently of the age of the subject. Yet, comparisons of $\%$ of open arm time and entries between agematched maze-naive versus maze-experienced animals revealed significant differences only in younger subjects. The lack of significant differences of previous maze experience in older animals is due to the paradoxical open arm avoidance previously observed rather than to an altered profile in drug 
response in the second trial of the maze. In other words, the apparent effect of age in the tolerance to midazolam should not be ascribed to an altered response to the drug but instead to the altered behaviour pattern in the re-exposure to the maze observed in drug-free animals: while in young animals there was a significant avoidance to open arms, re-exposure of old saline treated rats to the EPM was associated with a preference to open arms.

The paradoxical effect of aging in open arm avoidance, as well as the shift towards a predominant sedative response to benzodiazepines in aged animals, illustrates a qualitative change in emotional behaviour with increasing age that might influence the efficacy of anxiolytic drugs in elder subjects. The present results suggest that alterations in GABA-A receptor activity during the lifespan $[41,44]$ may underlie resistance to conventional anxiolytic agents. Thus, improved treatment outcome in anxiety disorders in older subjects will benefit from the design of pharmacological agents that are customized to meet the challenges of an altered neurochemical substrate during aging.

\section{References}

[1] Arevalo C, de Miguel R, Hernandez-Tristan R. Cannabinoid effects on anxiety-related behaviours and hypothalamic neurotransmitters. Pharmacol Biochem Behav 2001;70:123-31.

[2] Bertoglio LJ, Carobrez AP. Previous maze experience required to increase open arms avoidance in rats submitted to the elevated plusmaze model of anxiety. Behav Brain Res 2000;108:197-203.

[3] Bertoglio LJ, Carobrez AP. Anxiolytic effects of ethanol and phenobarbital are abolished in test-experienced rats submitted to the elevated plus-maze. Pharmacol Biochem Behav 2002;73:963-9.

[4] Bertoglio LJ, Carobrez AP. Anxiolytic-like effects of NMDA/glycine-B receptor ligands are abolished during the elevated plus-maze trial 2 in rats. Psychopharmacology 2003;170:335-42.

[5] Bertoglio LJ, Carobrez AP. Scopolamine given pre-Trial 1 prevents the one-trial tolerance phenomenon in the elevated plus-maze Trial 2. Behav Pharmacol 2004;15:45-54.

[6] Boguszewski P, Zagrodska J. Emotional changes related to age in rats - a behavioral analysis. Behav Brain Res 2002;133:323-32.

[7] Chakrabarti A, Ekuta JE, Onaivi ES. Neurobehavioral effects of anandamide and cannabinoid receptor gene expression in mice. Brain Res Bull 1998;45:67-74.

[8] Chaperon F, Thiebot MH. Behavioral effects of cannabinoid agents in animals. Crit Rev Neurobiol 1999;13:243-81.

[9] Craig D, Passmore AP, Fullerton KJ, Beringer TR, Gilmore DH, Crawford VL, et al. Factors influencing prescription of CNS medications in different elderly populations. Pharmacoepidemiol Drug Saf 2003;12:383-7.

[10] Cruz AP, Frei F, Graeff FG. Ethopharmacological analysis of rat behavior on the elevated plus-maze. Pharmacol Biochem Behav 1994;49:171-6.

[11] Dawson GR, Tricklebank MD. Use of elevated plus-maze in the search for novel anxiolytic agents. Trends Pharmacol Sci 1995;16:33-6.

[12] Dawson GR, Crawford SP, Stanhope KJ, Iversen SD, Tricklebank MD. One-trial tolerance to the effects of chlordiazepoxide on the elevated plus-maze may be due to locomotor habituation, not repeated drug exposure. Psychopharmacology 1994;113:570-2.

[13] Davies SN, Pertwee RG, Riedel G. Functions of cannabinoid receptors in the hippocampus. Neuropharmacology 2002;42:993-1007.
[14] File SE, Mabbut PS, Hitchcott PK. Characterisation of the phenomenon of "one trial tolerance" to the anxiolytic effect of chlordiazepoxide. Psychopharmacology 1990;110:98-101.

[15] File SE, Zangrossi H, Viana M, Graeff FG. Trial 2 in the elevated plus-maze: a different form of fear? Psychopharmacology 1993;111:491-4.

[16] Fernandes C, File SE. The influence of open arm ledges and maze experience in the elevated plus-maze. Pharmacol Biochem Behav 1996;54:31-40.

[17] Frussa-Filho R, Ribeiro RdeA. One-trial tolerance to the effects of chlordiazepoxide in the elevated plus-maze is not due to the acquisition of a phobic avoidance of open arms during initial exposure. Life Sci 2002;71:519-25.

[18] Griebel G, Rodgers RJ, Perrault G, Sanger DJ. Risk assessment behavior: evaluation of the utility in the study of 5-HT-related drugs in the rat elevated plus-maze test. Pharmacol Biochem Behav 1997;57:817-27.

[19] Griebel G, Moreau GL, Jenck F, Martin JR, Misslin R. Some critical determinants of the behavior of rats in the elevated plus-maze. Behav Proc 1993;29:129-38.

[20] Hascoet M, Bourin M, Couetoux du Tertre A. Influence of prior test experience on mice behavior using the four-plate test. Pharmacol Biochem Behav 1997;58:1131-8.

[21] Hogg S. A review of the validity and variability of the elevated plusmaze as an animal model of anxiety. Pharmacol Biochem Behav 1996;54:21-30.

[22] Holmes A, Rodjers AJ. Responses of Swiss-Webster mice to repeated plus-maze experience: further evidence for qualitative shift in emotional state? Pharmacol Biochem Behav 1998;60:473-88.

[23] Holmes A, Rodjers AJ. Influence of spatial and temporal manipulations on the anxiolytic efficacy of chlordiazepoxide in mice previously exposed to the elevated plus-maze. Neurosci Biobehav Rev 1999;23:971-80.

[24] Holmes A, Iles JP, Mayell SJ, Rodgers RJ. Prior test experience compromises the anxiolytic efficacy of chlordiazepoxide in the mouse light/dark exploration test. Behav Brain Res 2001;122:159-67.

[25] Imhof JT, Coelho ZM, Schimtt ML, Morato GS, Carobrez AP. Influence of gender and age on performance of rats in the elevated plus-maze. Behav Brain Res 1993;56:177-80.

[26] Labar KS, Cook CA, Torpey DC, Welsh-Bohmer KA. Impact of healthy aging on awareness and fear conditioning. Behav Neurosci 2004;118:905-15.

[27] Lister RG. Ethologically based animal models of anxiety disorders. Pharmacol Ther 1990;46:321-40.

[28] Marsicano G, Wotjak CT, Azad SC, Bisogno T, Rammes G, Cascio MG, et al. The endogenous cannabinoid system controls extinction of aversive memories. Nature 2002;418:530-4.

[29] Mato S, Pazos A. Influence of age, postmortem delay and freezing storage period on cannabinoid receptor density and functionality in human brain. Neuropharmacology 2004;46:716-26.

[30] McGregor IS, Dielenberg RA. Differential anxiolytic efficacy of a benzodiazepine on first versus second exposure to a predatory odor in rats. Psychopharmacology 1999;147:174-81.

[31] Onaivi ES, Green MR, Martin BR. Pharmacological characterization of cannabinoids in the elevated plus maze. J Pharmacol Exp Ther 1990;253:1002-9.

[32] Pellow S, Chopin P, File SE, Briley M. Validation of open:closed arm entries in an elevated plus-maze as a measure of anxiety in the rat. J Neurosci Methods 1985;14:149-67.

[33] Rodgers RJ, Cole JC. The elevated plus-maze: pharmacology, methodology and ethology. In: Cooper SJ, Hendrie CA, editors. Ethology and Psychopharmacology. Chichester: Wiley; 1994. p. 9-44.

[34] Rodgers RJ, Sheperd JK. Influence of prior maze experience on behavior and response to diazepam in the elevated plusmaze and light/dark tests of anxiety in mice. Psychopharmacology $1993 ; 113: 237-42$ 
[35] Rodgers RJ, Johnson NJT, Cole JC, Dewar CV, Kidd GR, Kimpson $\mathrm{PH}$. Plus-maze retest profile: importance of initial stages of trial 1 and response to post-trial cholinergic receptor blockade in mice. Pharmacol Biochem Behav 1996;54:41-50.

[36] Rodgers RJ, Johnson NJT, Carr J, Hodgson TP. Resistance of experientially induced changes in murine plus-maze behavior to altered retest conditions. Behav Brain Res 1997;6:71-7.

[37] Rodgers RJ, Haller J, Halasz J, Mikics E. 'One-trial sensitization' to the anxiolytic-like effects of cannabinoid receptor antagonist SR141716A in the mouse elevated plus-maze. Eur J Neurosci 2003;17:1279-86.

[38] Rodriguez de Fonseca F, Carrera MR, Navarro M, Koob GF, Weiss F. Activation of corticotropin-releasing factor in the limbic system during cannabinoid withdrawal. Science 1997;276:2050-4.

[39] Schlicker E, Kathmann M. Modulation of transmitter release via presynaptic cannabinoid receptors. Trends Pharmacol Sci 2001;22:565-72.
[40] Sulcova E, Mechoulam R, Fride E. Biphasic effects of anandamide. Pharmacol Biochem Behav 1998;59:347-52.

[41] Tehrani MH, Tate CA, al-Dahan MI. Age-related levels of GABA/benzodiazepine binding sites in cerebrum of F344 rats: effects of exercise. Neurobiol Aging 1995;16:199204.

[42] Treit D, Menard J, Royan C. Anxiogenic stimuli in the elevated plus-maze. Pharmacol Biochem Behav 1993;44:4639.

[43] Valjent E, Mitchell JM, Besson MJ, Caboche J, Maldonado R. Behavioural and biochemical evidence for interactions between Delta 9-tetrahydrocannabinol and nicotine. Br J Pharmacol 2002;135: 564-78.

[44] Wikinski SI, Acosta GB, Gravielle MC, Bonavita CD, Bisagno V, Fiszer de Plazas S, et al. Diazepam fails to potentiate GABA-induced chloride uptake and to produce anxiolytic-like action in aged rats. Pharmacol Biochem Behav 2001;68:721-7. 